\title{
Apo lipoprotein A1 gene polymorphisms predict cardio-metabolic risk in South Asian immigrants
}

\author{
Sunita Dodani ${ }^{\mathrm{a}, *}$, Rebecca Henkhaus ${ }^{\mathrm{b}}$, Lei Dong ${ }^{\mathrm{c}}$ and Merlin G. Butler ${ }^{\mathrm{b}}$ \\ ${ }^{a}$ Center for Post Polio Rehabilitation (A non-profit organization), KS, USA \\ ${ }^{\mathrm{b}}$ Departments of Psychiatry and Behavioral Sciences and Pediatrics, University of Kansas Medical Center, KS, \\ USA \\ ${ }^{\mathrm{c}}$ Department of Biostatistics, University of Kansas Medical Center, KS, USA
}

\begin{abstract}
Objectives: Coronary artery disease (CAD) is a leading cause of death globally with increasing burden in South Asians in the US. Specific genetic variants that influence CAD have not been fully assessed in South Asian Immigrants. The goal is to identify Apo lipoprotein A1 (APOA1) gene polymorphisms and their association with CAD risk factors, metabolic syndrome and dysfunctional HDL (Dys-HDL).

Methods: A community-based study on South Asians aged 35-65 years without CAD was conducted. APOA1 gene sequencing was performed and genotypes compared with cardiovascular findings.

Results: The prevalence of metabolic syndrome and dysfunctional-HDL was $29.7 \%$ and $26 \%$, respectively. Six novel APOA1 gene single nucleotide peptides (SNPs) were analyzed. Three of the six SNPs (G2, G3, and G5) were found to be associated with metabolic syndrome; G2 (T655C) $(p=0.044), \mathrm{G} 3$ (T756C) $(p=0.037)$ and G5 (T1001C) $(p=0.037)$. APOA1 gene SNP G1 (T319C) was highly correlated with low HDL levels $(p=0.001)$. In our study, both associations of APOA1 SNPs with metabolic syndrome and low HDL remained after age-adjustment.

Conclusion: Discovery of novel gene polymorphisms will help to understand further the causes of excess CAD risk in South Asians so that preventative strategies targeted to high-risk group can be developed.
\end{abstract}

Keywords: Coronary artery disease, risk factors, South Asian immigrants, polymorphisms, Apo Lipoprotein A1, dysfunctional high density lipoprotein

\section{Introduction}

Aggressive clinical and public health interventions have resulted in significant reduction in cardiovascular disease (CVDs) and mortality. However, CVD in general and coronary artery disease (CAD) in particular continue to be the leading causes of mortality and morbidity in the US, accounting for more than $40 \%$ of all deaths [1]. Moreover, there is troubling evi-

* Correspondence: Sunita Dodani, MD, PhD, FAHA, P O Box 25246 Shawnee Mission, KS 66225, USA. Tel.: +1 913663 2803; E-mail: soni.dodani@gmail.com. dence that the prevalence of CAD and its risk factors are on the rise in immigrant populations that constitute more than $11 \%$ of the US population. Event rates in South Asians (people with ancestors from the Indian subcontinent, i.e., India, Pakistan, Bangladesh, Nepal, Bhutan, and Sri Lanka) have doubled in the past two decades, with the prevalence of CAD in South Asian immigrants (SAIs) as 9.4\% [2-4]. South Asian immigrants exhibit a higher prevalence of CAD and risk factors compared with Caucasians [2-5]. These findings are not limited to the US [4-9]. Although South Asians represent the second largest and fastest growing Asian immigrant population in the US, little is known regarding their increased risk for CAD [7]. Not uniform 
groups, SAIs include ethnic subgroups with different cultures and practices, but as a whole, SAIs, compared to other populations, have much higher prevalence of type 2 diabetes (T2D), metabolic syndrome (MS), insulin resistance, central obesity, dyslipidemias [lower HDL cholesterol, increased lipoprotein a-Lp(a), higher triglycerides (TGs) and increased thrombotic tendency], and lower levels of physical activity [3-9]. SAIs as a whole have the highest prevalence of CAD $(21.5 \%$ in men and $15.9 \%$ in women) and a higher mortality due to CAD compared to other immigrant groups and Caucasians [10]. Further, CAD risk factors are present at a younger age in South Asians compared to other populations resulting in CAD at a younger age than in other populations [2]. Conventional risk factors, insulin resistance, or MS (although important in predicting CAD risk), may not fully account for the increased risk in SAIs $[9,10]$. Approximately one-third of CV events are not readily attributed to traditional $\mathrm{CV}$ risk factors [11], often referred to as the detection gap, suggesting that other non-traditional or "novel" conditions contribute to $\mathrm{CV}$ disease. Thus, a search for additional markers is warranted to promote early detection and prevention of CAD, especially in high-risk groups such as SAIs. Given the high prevalence of CAD and its risk factors in SAIs, a major challenge associated with primary prevention of CAD involves detection of early risk factors as well as early diagnosis of subclinical CAD in those individuals at a high CAD risk but are asymptomatic.

Among the numerous genetic and lifestyle factors associated with CAD, dyslipidemias are one of the most important. HDL cholesterol plays a protective role with low HDL as an independent risk factor for CAD [12]. This protective effect of HDL is related to its role as an anti-atherogenic, anti-oxidant, and anti-inflammatory agent preventing low-density lipoprotein (LDL) oxidation, primarily through Apo lipoprotein A-I (Apo A-I), the main protein component of HDL. Apo A-I is strongly correlated with low HDL levels and function [13]. However, several recent studies in patients with CAD have shown that HDL is not only ineffective as an antioxidant but, paradoxically, is a pro-oxidant assessed by its lipid peroxide content $[13,14]$.

South Asians in general and SAIs in particular are commonly known to have low HDL levels [5,6]. HDL is likely to be less effective at reverse cholesterol transport (RCT) along with an increased prevalence of metabolic syndrome (MS), T2D and CAD in this population [13-16]. However, presence of APOAl gene polymorphisms and associations with low HDL levels,
MS and sub-clinical CAD in this population has not been fully examined $[16,17]$. In addition, understanding of HDL functionality is important with respect to low HDL levels in SAIs. We predict that SAIs have specific $A P O A 1$ gene polymorphisms that may relate to low HDL levels and the increased CAD risk. The objective of the current study is to identify APOA 1 gene polymorphisms and their association with low HDL levels and other risk factors for CAD in SAIs in the United States. Further, to explore novel non-conventional risk markers for CAD, we determined the association of pro-inflammatory or dysfunction HDL (Dys-HDL) with novel APOA1 polymorphisms

\subsection{Apo lipoprotein A-I}

Structure and Function: Apo A-I (APOAl gene codes for Apo A-I protein) is the major protein component of HDL, consisting of 243 amino acids. It is synthesized mainly in the liver and to some extent in the small intestine. The inverse relationship between HDL and CAD has been attributed to the role of HDL and its major constituent, Apo A-I, involved in reverse cholesterol transport (RCT) $[18,19]$. HDL can be separated into two components, $\mathrm{HDL}_{2}$ and $\mathrm{HDL}_{3}$, with ultracentrifugation. HDL can also be separated into particles containing Apo A-I without Apo A-II and particles that contain both Apo A-I and Apo A-II [18,20].

The APOAl gene is present along with the APOC 3 and $A P O A 4$ genes on chromosome 11 (at 11q23.3-qter). It has been shown previously that one of the gene allele variants (A allele) of the APOAl gene contributes to the severity of CAD and low levels of HDL among Northern Indians [21].

\section{Methods}

The study received Institutional Review Board approval from both the University of Kansas Medical Center and Medical College of Georgia (now called Georgia Health Sciences University). Detailed study methods have been provided previously [15]. Briefly, a prospective cross-sectional study design was used with SAIs belonging to an Indian origin between the ages of 35-65 years and recruited from the main Hindu temples in the States of Georgia, Kansas and Missouri. This age range was chosen because CAD and risk factors occur at younger ages in SAIs compared to other populations [2]. The SAI population in the US is most readily accessed through their temples of 
worship. This approach was used, because no national level census or data are available on South Asians for providing an estimate of the total population within the US. Therefore, this study may not be generalizable, however, most SAIs who visit temples on weekends represent several ethnic groups. Information was obtained on socio-demographic status, ethnicity (based on spoken language), personal lifestyle characteristics, and both traditional and non-traditional risk factors for CAD. Twelve-hour fasting blood samples were collected for measurements of high sensitivity C-reactive protein (hsCRP), total lipid testing including total cholesterol, triglycerides (TGs), high density lipoprotein (HDL), low density lipoprotein (LDL), and lipoprotein a (Lp[a]). Insulin, fibrinogen, homocysteine and Apo A-I serum levels were also measured. The diagnosis of MS was made using the International Diabetes Federation (IDF) definition [22].

\section{Carotid ultrasound doppler for common carotid intima-media thickness (CCA-IMT)}

Assessment of common carotid artery intima-media thickness (CCA-IMT) is a well-recognized method in diagnosing atherosclerosis [23]. Furthermore, CCAIMT has been used recently, not only as a surrogate end point for atherosclerosis of CAD, but as an accepted indicator of the presence and extent of CAD [24]. Details on carotid CCA-IMT has been published previously [25]. Briefly, B-mode ultrasound scanning of bilateral carotid arteries was performed by a trained non-invasive vascular ultrasound technician using a SonoCalc ${ }^{\mathrm{TM}}$ IMT machine (SonoSite, Inc Bothell, WA) with a $10.0 \mathrm{MHz}$ linear array transducer. In order to maintain consistency, the same trained ultrasound technicians were selected at each site to obtain the CCA-IMT scanning results. Both common carotid arteries were scanned with the subject in the supine position. A total of four images were obtained on each side, $1 \mathrm{~cm}$ proximal to the carotid bulb using an anterior approach. Images were obtained at an angle to show good lumen-intima and media-adventitia demarcation and were recorded and stored on a disk for offline analysis. ECG leads were placed to obtain enddiastolic measurements. The CCA-IMT approach for IMT measurements was preferred because of reproducibility [26] and predictability for future cardiovascular events [27]. Any focal thickening of the intimamedia complex or carotid plaque was not included in the analysis. Cardiologists were blinded to the partic- ipants' clinical information and analyzed IMT results using automated edge detection technology software (Sono Calc $^{\text {TM }}$ IMT). Measurements of the far wall of the carotid artery were done as they are more indicative of the true thickness of the arterial wall [27]. A CCAIMT cut-off of $\geqslant 0.80 \mathrm{~mm}$ was chosen and analyzed as positive with IMT measurements based on the available evidence supporting the presence of sub-clinical CAD [26,27].

\subsection{Assessment of dysfunctional HDL (Dys-HDL)}

According to National Cholesterol Education Program (NCEP) ATP III guidelines, an HDL level < $40 \mathrm{mg} / \mathrm{dl}$ is defined as an independent risk factor for CAD and low HDL is often present in high-risk patients with $\mathrm{CAD}$ [27]. Current data indicates that a $1 \%$ increase in HDL serum concentration can decrease $\mathrm{CV}$ risk by $2-3 \%$, independent of LDL levels [27]. However, HDL can have this protective effect only if it is functional. We have shown previously the presence of Dys-HDL in $50 \%$ of SAIs without CAD and found an association with lipoprotein [a], low HDL and CCAIMT (age-adjusted) [15,16].

The diagnosis of Dys-HDL has historically been made with a cell-based assay that requires endothelial cells, smooth muscle cells, and monocytes. However, the use of a cell-based assay is not practical for large-scale studies. Hence, a cell-free assay has been developed to detect dysfunctional HDL $[28,29]$. The details on Dys-HDL assessment with cell-free assays and the HDL inflammatory index have been published previously $[15,16,30]$.

\subsection{DNA isolation and APOAl gene sequencing}

Each whole blood sample (4 mls) was assigned a unique DNA identification code. Genomic DNA was extracted from whole blood (2 mls) using the Qiagen FlexiGene DNA Kit (Qiagen ${ }^{\circledR}$, Valencia, CA, USA) which yields $4-12 \mu \mathrm{g}$ of DNA. An aliquot of DNA was diluted and the absorbance at $\lambda 260 \mathrm{~nm}$ and $\lambda$ $280 \mathrm{~nm}$ measured using an Eppendorf Biophotometer for verification of quality and concentration. DNA samples were diluted to $50 \mathrm{ng} / \mu \mathrm{l}$ and stored at $-80^{\circ} \mathrm{C}$.

PCR amplification was performed on genomic DNA to amplify a $1683 \mathrm{bp}$ fragment of the APOAl gene encompassing the SNPs to be analyzed using forward 5' CGGCAGAGACTATGTGTCCCAG 3' and reverse 5' CCAGATCCTTGCTCATCTCC 3' PCR primers. The PCR fragment was purified using the QIA 
quick PCR purification kit (Qiagen, Valencia, CA). Sequencing was performed commercially by ACGT Inc. (Wheeling, IL) and results analyzed using Ridom Trace Edit software (Ridom Bioinformatics, Würzburg, Germany) and NCBI BLAST sequence analysis. The reference sequence used was NCBI RefSeq NC_000011.9, derived from the Genome Reference Consortium Human Build 37 (GRCh37), Primary Assembly (http:// www.ncbi.nlm.nih.gov/gene).

\subsection{Data analysis and power calculation}

We enrolled 129 first generation SAIs from different ethnic backgrounds. Our pilot study consisted of a fixed sample of 130 participants to assess the association of a novel APOAl gene polymorphism with DysHDL, MS, low HDL and sub-clinical CAD using CCAIMT as a surrogate marker for atherosclerosis. APOAI gene analysis studies were performed on 94 subjects. The power calculation for assessing Dys-HDL (primary outcome) was based on a chi-square contingency table analysis [Dys-HDL (Yes/No) vs. CCA-IMT (Yes/No)], and from available data on CCA-IMT in South Asians [25]. Assuming that 20\% of 130 individuals have positive CCA-IMT, we calculated a $90 \%$ power at $5 \%$ alpha level and $85 \%$ power at $1 \%$ alpha level to detect the Dys- HDL difference in two groups.

Baseline socio-demographic characteristics and CAD risk factors were summarized by frequency distributions and percentages for qualitative measures and means and standard deviations for quantitative measures. Maximum likelihood estimates and asymptotic 95\% confidence intervals were calculated for the prevalence of disease/diagnosis outcome measures. Bivariate tests of association and odds ratios were performed by simple logistic regression. Multiple logistic regression models were used to assess the relative importance of variables found to be significantly associated with the outcome from the bivariate assessments. All statistical tests were two-sided and performed at the 0.05 level of significance.

\section{Results}

Of the total sample, complete information was obtained on 129 subjects, constituting our study sample (Table 1). Partial APOA1 gene sequencing was completed in 94 subjects. The mean age was $51 \pm 9.23$ years with almost an equal number of males and females (Table 1). The study group presented a ho-
Table 1

Socio-demographics of study sample $(n=129)$

\begin{tabular}{lcc}
\hline Variable & & $\mathrm{n}(\%)$ \\
\hline Age (years) & Male & $51.30 \pm 9.23^{*}$ \\
& Female & $51.04 \pm 9.64^{*}$ \\
Gender & Male & $76(58.6)$ \\
Ethnicity & Female & $53(41.4)$ \\
& & \\
& South Indian & $33(25.6)$ \\
& Guajarati & $23(17.8)$ \\
& Hindi & $23(17.8)$ \\
& Bengali & $10(7.8)$ \\
Work Type & Punjabi & $8(6.2)$ \\
& Other & $32(26.2)$ \\
& Employee full time & $91(70.5)$ \\
& Homeworker & $14(10.9)$ \\
& Employee part time & $9(7.0)$ \\
& Unemployed & $6(4.7)$ \\
& Other & $8(6.2)$ \\
& & \\
& Postgraduate & $67(51.9)$ \\
& Graduate & $30(23.3)$ \\
& Undergraduate & $24(18.6)$ \\
& Other & $1(0.8)$ \\
\hline
\end{tabular}

${ }^{*}$ Means \pm SD (Standard Deviation).

mogenous mixture of various ethnicities including Hindi speaking (18\%), Gujratis (18\%), and South Indians (26\%). More than $50 \%$ received up to post-graduate level education. The prevalence of CAD risk factors was (a) hypertension- 45\% (b) high cholesterol $\geqslant 200$ $\mathrm{mg} / \mathrm{dl}-41.6 \%$, (c) HDL $<40 \mathrm{mg} / \mathrm{dl}-26.4 \%$ (d) LDL $\geqslant 150 \mathrm{mg} / \mathrm{dl}-16.9 \%$, (e) Lp[a]-35.7\% (f) hsCRP ( $\geqslant$ $5)-48.74 \%,(\mathbf{g}) \mathrm{BMI} \geqslant 23-78.4 \%$ (h) obesity (BMI $\geqslant$ 30)-18.2\%; and (i) family history of CAD and T2D was $34.4 \%$ and $48.4 \%$, respectively (Table 2). About $80 \%$ were physically active, based on questionnaire survey data (not shown). Sub-clinical CAD using CCA-IMT $\geqslant 0.8 \mathrm{~mm}$, as a surrogate marker for atherosclerosis, was seen in $38.5 \%$ of subjects. Obesity was also reflected as an increase in waist circumferences in both genders (Table 2). Based on the International Diabetes Federation (IDF) criteria, MS was seen in $29.7 \%$ of SAIs without CAD.

\subsection{Association of APOAl gene SNPs with MS, CCA-IMT and intermediate phenotypes}

DNA was analyzed for six APOA1 gene polymorphisms or SNPs in the SAIs without known CAD (Tables 3 and 4). When individual SNPs were tested directly against MS and CCA-IMT as outcome variables, three of the six SNPs (G2, G3, and G5) were found to 
Table 2

Coronary artery diseases (CAD) risk factors and markers $(n=129)$

\begin{tabular}{|c|c|c|c|}
\hline \multicolumn{2}{|c|}{ Variables } & \multirow[t]{2}{*}{$\mathrm{n}(\%)$} & \multirow{2}{*}{$\frac{\text { Mean } \pm \text { Std }}{26.37 \pm 5.08}$} \\
\hline BMI & & & \\
\hline & Normal $(<23)$ & $27(21.62)$ & $21.84 \pm 1.68$ \\
\hline & Overweight (23-30) & $76(60.14)$ & $25.82 \pm 2.05$ \\
\hline & Obese $(\geqslant 30)$ & $22(18.24)$ & $34.07 \pm 6.45$ \\
\hline \multirow[t]{3}{*}{ Total LDL } & & & $117.63 \pm 35.61$ \\
\hline & Normal $(<150 \mathrm{mg} / \mathrm{dl})$ & $103(83.06)$ & $106.08 \pm 24.73$ \\
\hline & Abnormal $(\geqslant 150 \mathrm{mg} / \mathrm{dl})$ & $21(16.94)$ & $174.95 \pm 24.44$ \\
\hline \multirow[t]{3}{*}{ Total HDL } & & & $48.38 \pm 10.99$ \\
\hline & Normal (> 40 mg/dl) & $92(73.6)$ & $52.95 \pm 8.98$ \\
\hline & Abnormal $(\leqslant 40 \mathrm{mg} / \mathrm{dl})$ & $33(26.4)$ & $35.79 \pm 4.31$ \\
\hline \multirow[t]{3}{*}{ Dys-HDL } & & & $0.83 \pm 0.74$ \\
\hline & Normal $(<1.0)$ & $88(73.95)$ & $0.53 \pm 0.17$ \\
\hline & Dysfunctional $(\geqslant 1.0)$ & $31(26.05)$ & $1.71 \pm 1.02$ \\
\hline \multirow[t]{3}{*}{ Total Cholesterol } & & & $193.17 \pm 38.97$ \\
\hline & Normal $(<200$ mg/dl) & $73(58.4)$ & $167.74 \pm 22.34$ \\
\hline & Abnormal $(\geqslant 200 \mathrm{mg} / \mathrm{dl})$ & $52(41.6)$ & $229.31 \pm 27.37$ \\
\hline \multirow[t]{3}{*}{ Triglycerides } & & & $160.44 \pm 114.56$ \\
\hline & Normal $(<150$ mg/dl $)$ & $73(58.4)$ & $99.23 \pm 26.88$ \\
\hline & Abnormal $(\geqslant 150 \mathrm{mg} / \mathrm{dl})$ & $52(41.6)$ & $246.90 \pm 134.70$ \\
\hline \multirow[t]{3}{*}{ Lipoprotein [a] } & & & $13.61 \pm 18.99$ \\
\hline & Normal $(<10$ mg/dl) & $79(64.23)$ & $4.59 \pm 1.79$ \\
\hline & Abnormal $(\geqslant 10 \mathrm{mg} / \mathrm{dl})$ & $44(35.77)$ & $30.02 \pm 24.46$ \\
\hline \multirow[t]{3}{*}{ Apo lipoprotein A-I } & & & $150.36 \pm 31.94$ \\
\hline & Normal (94-176 mg/dl) & $95(76.0)$ & $142.06 \pm 22.19$ \\
\hline & Abnormal (else) & $30(24.0)$ & $178.13 \pm 41.30$ \\
\hline \multirow[t]{3}{*}{ hsCRP } & & & $3.32 \pm 2.56$ \\
\hline & Normal $(<5$ mg/L) & $63(51.22)$ & $1.24 \pm 1.09$ \\
\hline & Abnormal $(\geqslant 5 \mathrm{mg} / \mathrm{L})$ & $60(48.78)$ & $5.55 \pm 1.60$ \\
\hline \multirow[t]{3}{*}{ Homocysteine } & & & $10.34 \pm 7.71$ \\
\hline & Normal (< 12 umol/L) & $74(77.89)$ & $7.96 \pm 2.06$ \\
\hline & Abnormal $(\geqslant 12 \mathrm{umol} / \mathrm{L})$ & $21(22.11)$ & $18.79 \pm 13.08$ \\
\hline \multirow[t]{3}{*}{ CCA-IMT } & & & $0.73 \pm 0.16$ \\
\hline & $\operatorname{Normal}(<0.8 \mathrm{~mm})$ & $71(68.54)$ & $0.649 \pm 0.094$ \\
\hline & Abnormal $(\geqslant 0.8 \mathrm{~mm})$ & $32(31.46)$ & $0.916 \pm 0.15$ \\
\hline \multirow[t]{3}{*}{ Waist Circumference $(\mathrm{cm})$} & & & $93.72 \pm 14.08$ \\
\hline & Male & $61(48.66)$ & $95.53 \pm 12.74$ \\
\hline & Female & $46(27.98)$ & $91.47 \pm 15.58$ \\
\hline \multirow[t]{2}{*}{ Physical Activity } & No & $20(15.50)$ & \\
\hline & Yes & $109(84.50)$ & \\
\hline \multirow[t]{2}{*}{ Smoking } & No & $121(93.80)$ & \\
\hline & Yes & $8(6.20)$ & \\
\hline \multirow[t]{2}{*}{ Type 2 Diabetes (T2D) } & No & $89(69.53)$ & \\
\hline & Yes & $39(30.47)$ & \\
\hline \multirow[t]{2}{*}{ Hypertension $\$$} & No & $70(54.69)$ & \\
\hline & Yes & $58(45.31)$ & \\
\hline \multirow[t]{2}{*}{ Family History of T2D } & No & $48(43.24)$ & \\
\hline & Yes & $63(56.76)$ & \\
\hline \multirow[t]{2}{*}{ Family History of CAD } & No & $67(60.36)$ & \\
\hline & Yes & $44(39.64)$ & \\
\hline \multirow[t]{2}{*}{${ }^{\dagger}$ MS Prevalence } & No & $68(53.1)$ & \\
\hline & Yes & $38(29.7)$ & \\
\hline
\end{tabular}

${ }^{\dagger}$ MS defined by International Diabetes Federation (IDF); Dys-HDL = Dysfunctional HDL measured by HDL Inflammatory index; hsCRP $=$ high sensitivity $\mathrm{C}$ reactive protein; CCA$\mathrm{IMT}=$ Common carotid artery intima media thickness; ${ }^{\$}$ History/examination and/or blood test. 
Table 3

Association of Apo A1 Gene Polymorphisms (un-adjusted) with HDL, Dys-HDL, IMT, and MS $(n=94)$

\begin{tabular}{|c|c|c|c|c|c|c|c|c|c|}
\hline \multicolumn{2}{|c|}{ Apo A1 SNPs } & \multicolumn{2}{|c|}{ Dys-HDL } & \multicolumn{2}{|c|}{ CCA-IMT } & \multicolumn{2}{|c|}{ HDL } & \multicolumn{2}{|c|}{ MS } \\
\hline & & $<1$ & $\geqslant 1$ & No & Yes & $\geqslant 40 \mathrm{mg} / \mathrm{dl}$ & $<40 \mathrm{mg} / \mathrm{dl}$ & No & yes \\
\hline \multirow[t]{4}{*}{ G1-P319 (T319C) } & WT & $40(48.2)^{*}$ & $8(9.64)$ & $31(45.6)$ & $7(10.3)$ & $31(36.5)$ & $18(21.2)$ & $36(42.4)$ & $13(15.3)$ \\
\hline & Heterozygous & $23(27.7)$ & $6(7.23)$ & $20(29.4)$ & $5(7.35)$ & $29(34.1)$ & $0(0.0)$ & $25(29.4)$ & $4(4.71)$ \\
\hline & Mutant & $5(6.02)$ & $1(1.20)$ & $4(5.88)$ & $1(1.47)$ & $5(5.88)$ & $2(2.35)$ & $3(3.53)$ & $4(4.71)$ \\
\hline & P-Value ${ }^{\$}$ & \multicolumn{2}{|c|}{0.902} & \multicolumn{2}{|c|}{0.987} & \multicolumn{2}{|c|}{0.001} & \multicolumn{2}{|c|}{0.053} \\
\hline \multirow[t]{4}{*}{ G2-P655(T655C) } & WT & $10(11.9)$ & $2(2.38)$ & $11(15.9)$ & $1(1.45)$ & $9(10.6)$ & $3(3.53)$ & $12(14.1)$ & $0(0.0)$ \\
\hline & Heterozygous & $20(23.8)$ & $8(9.52)$ & $15(21.7)$ & $5(7.25)$ & $21(24.7)$ & $8(9.41)$ & $22(25.9)$ & $7(8.24)$ \\
\hline & Mutant & $39(46.4)$ & $5(5.95)$ & $30(43.5)$ & $7(10.1)$ & $34(40.0)$ & $10(11.8)$ & $29(34.1)$ & $15(17.7)$ \\
\hline & P-Value & \multicolumn{2}{|c|}{0.187} & \multicolumn{2}{|c|}{0.589} & \multicolumn{2}{|c|}{0.895} & \multicolumn{2}{|c|}{0.044} \\
\hline \multirow[t]{4}{*}{ G3-P756(T756C) } & WT & $10(11.8)$ & $2(2.35)$ & $11(15.7)$ & $1(1.43)$ & $9(10.5)$ & $3(3.49)$ & $12(14.0)$ & $0(0.0)$ \\
\hline & Heterozygous & $19(22.4)$ & $8(9.41)$ & $14(20.0)$ & $5(7.14)$ & $20(23.3)$ & $8(9.3)$ & $21(24.4)$ & $7(8.14)$ \\
\hline & Mutant & $41(48.2)$ & $5(588)$ & $31(44.3)$ & $8(11.4)$ & $35(40.7)$ & $11(12.8)$ & $30(34.9)$ & $16(18.7)$ \\
\hline & P-Value & \multicolumn{2}{|c|}{0.127} & \multicolumn{2}{|c|}{0.601} & \multicolumn{2}{|c|}{0.904} & \multicolumn{2}{|c|}{0.037} \\
\hline \multirow[t]{4}{*}{ G4-P938(C938T) } & WT & $52(61.2)$ & $12(14.1)$ & $42(60.0)$ & $12(17.1)$ & $51(59.3)$ & $15(17.44)$ & $51(59.3)$ & $15(17.4)$ \\
\hline & Heterozygous & $17(20.0)$ & $3(3.53)$ & $13(18.6)$ & $2(2.86)$ & $13(15.1)$ & $6(6.98)$ & $12(14.0)$ & $7(8.14)$ \\
\hline & Mutant & $1(1.18)$ & $0(0)$ & $1(1.43)$ & $0(0)$ & $0(0)$ & 1 (1.16) & $0(0)$ & $1(1.16)$ \\
\hline & P-Value & \multicolumn{2}{|c|}{0.833} & \multicolumn{2}{|c|}{0.775} & \multicolumn{2}{|c|}{0.169} & \multicolumn{2}{|c|}{0.093} \\
\hline \multirow[t]{4}{*}{ G5-P1001 (T1001C) } & WT & $10(11.4)$ & $2(2.27)$ & $11(15.1)$ & $1(1.37)$ & $9(10.1)$ & $3(3.4)$ & $12(13.5)$ & $0(0.0)$ \\
\hline & Heterozygous & $28(31.8)$ & $9(10.2)$ & $22(30.1)$ & $6(8.22)$ & $28(31.5)$ & $10(11.2)$ & $27(30.3)$ & $11(12.4)$ \\
\hline & Mutant & $35(39.8)$ & $4(4.55)$ & $25(34.25)$ & $8(11.0)$ & $29(32.6)$ & $10(11.2)$ & $25(28.1)$ & $14(15.7)$ \\
\hline & P-Value & \multicolumn{2}{|c|}{0.289} & \multicolumn{2}{|c|}{0.679} & \multicolumn{2}{|c|}{0.995} & \multicolumn{2}{|c|}{0.037} \\
\hline \multirow[t]{4}{*}{ G6-P1149(C1149T) } & WT & $67(76.1)$ & $14(15.9)$ & $52(71.2)$ & 15 (20.6) & $60(67.4)$ & $22(24.7)$ & $59(66.3)$ & $23(25.8)$ \\
\hline & Heterozygous & $6(6.82)$ & $1(1.14)$ & $6(8.22)$ & $0(0)$ & $6(6.74)$ & $1(1.12)$ & $5(5.62)$ & $2(2.25)$ \\
\hline & Mutant & $0(0)$ & $0(0)$ & $0(0)$ & $0(0)$ & $0(0)$ & $0(0)$ & $0(0)$ & $0(0)$ \\
\hline & P-Value & 0.4 & & & & & & 0.6 & \\
\hline
\end{tabular}

Dys-HDL, Dysfunctional HDL measure by HDL Inflammatory index, (LDL+HDL)/LDL; CCA-IMT, Common carotid artery intima media thickness; MS, Metabolic Syndrome, Central obesity and two or more of fasting glucose ( $\geqslant 100 \mathrm{mg} / \mathrm{dl}$ or T2D), obesity, HDL ( $\geqslant 40 \mathrm{mg} / \mathrm{dl})$, Blood pressure $(\geqslant 130 / \geqslant 85 \mathrm{mmHg})$; and Triglycerides $(\geqslant 150 \mathrm{mg} / \mathrm{d}) .{ }^{*} \mathrm{n}(\%){ }^{\$}$ Fisher - Exact test.

Table 4

Apo A-I Gene Polymorphisms (Age-adjusted) with HDL, Dys-HDL, IMT, and MS ( $n=94)$

\begin{tabular}{|c|c|c|c|c|c|c|c|c|c|c|c|c|}
\hline & \multicolumn{2}{|c|}{$\begin{array}{l}\text { G1-P319 } \\
\text { (T319C) }\end{array}$} & \multicolumn{2}{|c|}{$\begin{array}{l}\text { G2-P655 } \\
\text { (T655C) }\end{array}$} & \multicolumn{2}{|c|}{$\begin{array}{c}\text { G3-P756 } \\
\text { (T756C) }\end{array}$} & \multicolumn{2}{|c|}{$\begin{array}{c}\text { G4-P938 } \\
\text { (C938T) }\end{array}$} & \multicolumn{2}{|c|}{$\begin{array}{c}\text { G5-P1001 } \\
\text { (T1001C) }\end{array}$} & \multicolumn{2}{|c|}{$\begin{array}{r}\text { G6-P1149 } \\
\text { (C1149T) }\end{array}$} \\
\hline & $\mathrm{X}^{2}$ & $\mathrm{P}$ & $\mathrm{X}^{2}$ & $\mathrm{P}$ & $\mathrm{X}^{2}$ & $\mathrm{P}$ & $\mathrm{X}^{2}$ & $\mathrm{P}$ & $\mathrm{X}^{2}$ & $\mathrm{P}$ & $\mathrm{X}^{2}$ & $\mathrm{P}$ \\
\hline$\downarrow$ HDL & 15.917 & $<0.0001$ & 0.921 & 0.337 & 0.695 & 0.405 & 3.028 & 0.082 & 0.059 & 0.808 & 1.900 & 0.169 \\
\hline Dys-HDL & 0.253 & 0.615 & 2.243 & 0.134 & 2.824 & 0.093 & 0.466 & 0.495 & 2.054 & 0.152 & 0.056 & 0.813 \\
\hline MS & 0.008 & 0.929 & 7.091 & 0.008 & 7.245 & 0.007 & 5.417 & 0.020 & 6.988 & 0.008 & 0.125 & 0.724 \\
\hline CCA-IMT & 0.077 & 0.781 & 0.163 & 0.686 & 0.285 & 0.093 & 1.274 & 0.259 & 1.576 & 0.209 & 0.0001 & 0.994 \\
\hline
\end{tabular}

$\$$ P-Values from the Logistical regression Dys-HDL = Dysfunctional HDL measure by HDL Inflammatory index using cell free assay; CCA-IMT $=$ Common carotid artery intima media thickness; MS = Metabolic Syndrome defined by International Diabetes Federation definition [Central obesity and two or more of fasting glucose $(\geqslant 100 \mathrm{mg} / \mathrm{dl}$ or T2D), obesity, HDL ( $\geqslant 40 \mathrm{mg} / \mathrm{dl})$, Blood pressure $(\geqslant 130 / \geqslant 85 \mathrm{mmHg})]$.

be associated with MS: G2 (T655C) $(p=0.044), \mathrm{G} 3$ (T756C) $(p=0.037)$ and $\mathrm{G} 5(\mathrm{~T} 1001 \mathrm{C})(p=0.037)$. The APOA 1 gene SNP G1 (T319C) was highly correlated with low HDL levels $(p=0.001)$. Both associations of APOA1 SNPs with MS and low HDL remained after age-adjustment (Table 4). Further, odds ratio analysis revealed the importance of APOAI SNP association with Dys-HDL. The odds of the presence of two of the SNPs, i.e., G4 (C938T) and G5 (T1001C), with DysHDL was $2.516(1.16,5.47)$ and $2.497(1.27,4.92)$, respectively as compared to absence of Dys-HDL. Also, the odds of having SNP G2 (T655C) and G3 (T756C) with MS was $2.791(1.31,5.94)$ and $2.799(1.32,5.92)$, respectively as compared to those without MS. However, APOA 1 SNP association with CCA-IMT did not reach statistical significance and may be attributed to a small sample size in our study.

\section{Discussion}

The present study is unique and the first of its kind to focus on SAIs with dyslipidemias and MS and in identifying a significant association with APOAl gene polymorphisms with CAD intermediate outcomes. Several recent studies including, the INTERHEART case- 
Table 5

Odds Ratio of Apo A1 gene polymorphisms) with HDL, Dys-HDL, CCA-IMT, and MS ( $n=94)$

\begin{tabular}{lllllll}
\hline & G1-P319(T319C) & G2-P655(T655C) & G3-P756(T756C) & G4-P938(C938T) & G5-P1001(T1001C) & G6-P1149(C1149T) \\
\hline$\downarrow$ HDL & $0.088(0.03,0.29)$ & $0.711(0.36,1.43)$ & $0.747(0.38,1.48)$ & $2.021(0.92,4.46)$ & $0.920(0.47,1.79)$ & $0.233(0.03,1.85)$ \\
Dys-HDL & $1.224(0.56,2.69)$ & $0.560(0.26,1.20)$ & $0.522(0.24,1.11)$ & $\mathbf{2 . 5 1 6}(\mathbf{1 . 1 6}, \mathbf{5 . 4 7})$ & $\mathbf{2 . 4 9 7}(\mathbf{1 . 2 7 , 4 . 9 2})$ & $0.828(0.17,3.95)$ \\
MS & $1.033(0.51,2.11)$ & $\mathbf{2 . 7 9 1}(\mathbf{1 . 3 1 , 5 . 9 4})$ & $\mathbf{2 . 7 9 9}(\mathbf{1 . 3 2}, \mathbf{5 . 9 2})$ & $0.515(0.16,1.63)$ & $1.659(0.75,3.66)$ & $0.786(0.21,3.00)$ \\
CCA-IMT & $0.885(0.37,2.10)$ & $1.190(0.51,2.77)$ & $1.254(0.55,2.88)$ & $0.710(0.27,1.90)$ & $0.574(0.27,1.23)$ & $<0.001(<0.001,>999)$ \\
\hline
\end{tabular}

Dys-HDL = Dysfunctional HDL measure by HDL Inflammatory index, (LDL+HDL)/LDL; CCA-IMT = Common carotid artery intima media thickness; MS = Metabolic Syndrome defined by International Diabetes Federation (IDF) definition i.e. Central obesity and two or more of fasting glucose ( $\geqslant 100 \mathrm{mg} / \mathrm{dl}$ or T2D), obesity, HDL ( $\geqslant 40 \mathrm{mg} / \mathrm{dl})$, Blood Pressure ( $\geqslant 130 / \geqslant 85 \mathrm{mmHg})$; and Triglycerides $(\geqslant 150 \mathrm{mg} / \mathrm{d})$.

control study showed that nine risk factors (dyslipidemia, diabetes, hypertension, abdominal obesity, tobacco exposure, physical inactivity, psychosocial stressors, low fruit and vegetable intake, and no alcohol consumption) contributed to the risk of myocardial infarction (MI) globally [31-33]. The ratio of Apo lipoprotein (Apo) B/A-I is considered the strongest MI risk factor and accounts for $54 \%$ of the total population attributable risk for MI $[31,34]$. Apo A-I is the main protein of HDL which is responsible for RCT. Although various factors such as genetic variation, diet, exercise, alcohol, smoking, hormones, and certain drugs can significantly influence the levels of HDL and Apo A-I [35], family and twin studies have demonstrated a strong genetic heritability accounting for up to $66 \%$ of the variability of HDL and Apo A-I levels [18,36]. Furthermore, $40-60 \%$ of the inter-individual variation in HDL concentrations is controlled at the gene level [37]. The strong positive correlation between plasma levels of Apo A-I and HDL suggests that APOAl gene polymorphisms may be linked to the variability in HDL levels as well as to its dysfunction [36,37].

More than 40 APOAl gene polymorphisms have been identified in several ethnic populations, including South Asians [21,30,37-44]. Each polymorphism may correlate with differing HDL activity and levels. However, not all APOA1 polymorphisms are associated with CAD. Further, several point mutations have been identified, and one in particular is associated with low levels of HDL but not with an increased CAD risk and is, instead, associated with a reduction in CAD risk [40]. One such $A P O A 1$ mutation encodes the Apo A-I Milano (Apo A-I $\mathrm{I}_{\text {Arg } 173 C y s}$ ) protein.

Qualitative differences in HDL particles, mediated through genetic variability in APOA 1 and other genes, may be as important as quantitative differences in plasma HDL level in determining CAD risk. Therefore, the identified nine risk factors are themselves potentially influenced by genetic variants, which, could act on their own, or in combination with other genetic or lifestyle factors. Genetic variants that influence these risk fac- tors may also be associated with CAD $[45,46]$. However, recent studies identifying genetic associations with $\mathrm{MI}$ and/or CAD risk factors have largely been conducted among whites [45]. However, whether these findings can be extended to other ethnic groups remain to be demonstrated. In fact, the recent association between chromosome 9 variants and CHD, observed in Caucasians, was not replicated in African-Americans [47]. In addition, SNPs in several lipid-related genes seem to be strongly associated with plasma lipids [47] but inconsistently with CAD. However, recent genome-wide association studies have produced several robust genetic associations with lipid levels and CAD $[47,48]$.

Our results are consistent with the results of these recent genome-wide association studies of blood lipid levels and MS and we identified to be significantly associated with MS and low HDL in SAIs, a group not well represented in research studies. Our collective findings, raise the question of whether HDL levels as measured by current assays, is a marker or mediator of coronary artery disease, now knowing the role of non-functional HDL in sub-clinical CAD measurable by CCA-IMT. Certain single-gene conditions characterized by low or very low HDL levels have premature coronary artery disease as one of their manifestations (for example, Tangier disease, which results from mutations in the $A B C A 1$ gene), whereas others leading to low HDL levels do not (e.g., Apo A-I-Milano protein). In fact, recent data have shown that HDL particles containing Apo A-I-Milano is more effective than HDL containing normal Apo A-I levels at maintaining endothelial cell homeostasis under stress, due to up -regulation of endothelial nitric oxide synthase expression and down-regulation of vascular cell adhesion molecule expression [48]. Thus, qualitative differences in the HDL particles, mediated through genetic variability in APOAl and other genes, may be as important as quantitative and qualitative differences in plasma HDL level in determining CAD risk.

People affected by MS are at an increased risk of CAD and T2D, which are large and rapidly-increasing 
causes of illness and death globally. South Asians in general and SAIs in particular have a high prevalence of the MS compared with Europeans, and MS traits are highly heritable in this group [49]. Therefore, MS and its components are a major health concern, particularly in SAIs. The genome-wide association approach has met with some success in dyslipidemia, T2D and obesity phenotypes, with most studies to date being conducted in Europeans $[49,50]$. Our study has further confirmed a number of previously reported associations, in some cases for the first time in SAIs, and identified novel suggestive associations of APOA 1 gene polymorphisms with MS, requiring further confirmation.

The MS consists of a number of phenotypes that tend to co-occur, raising the question of whether or not they have common genetic mechanisms [50-52]. A number of definitions for the MS have been developed over the years, including those proposed by IDF, National Cholesterol Education Program Adult Treatment Panel III (NCEP ATPIII), or the World Health Organization (WHO) [53]. We chose the IDF definition, which is the most recent and incorporates ethnicity by providing different criteria for MS in different ethnic groups [53]. Most published associations for MS are only with individual component phenotypes, or in some cases with multiple phenotypes but not matching any of the above definitions. Joy et al. [54] reviewed a large number of genetic associations and linkage studies for MS using all definitions, and concluded that these studies have not provided confirmed associations. Our results from SAIs also found no evidence for common genetic mechanisms underlying MS, despite its high prevalence in this population. More work is needed to further understand MS components interactions with genotypes using genome-wide association studies as suggested by other authors [52].

Increased CCA-IMT has been associated with the extent and severity of CAD, and it is also an independent predictor of future MI [24]. A recent review summarizes the current knowledge of the effects of APOAI polymorphisms on CCA-IMT [55]. Genetic polymorphisms of APOA1/CIII/AIV, APOE and APOB have been suggested to modulate plasma lipid levels as well as the risk of CAD in Caucasians [55]. However, the effects of the polymorphisms in APOAl on CCA-IMT especially in SAIs are poorly known. Though we could not find association between novel APOA1 polymorphisms and CCA-IMT; however, our study brings attention towards an increased need for large-scale studies.

This study has provided novel preliminary results; however, several limitations of this study must be con- sidered including the cross-sectional design, which precludes any discussion on cause and effect. A longitudinal study would be needed to establish the temporal relationship. A smaller sample size in our study due to budget limitations and generalized results to all South Asian ethnic groups are also potential limitations. Further research is warranted to evaluate the diagnostic and prognostic utility of Apo A-I interactions with phenotypes related to CAD risk in this high risk group.

\section{Conclusion}

Apo A-I is the major protein component of HDL and known to be associated with HDL levels and its function. Epidemiologic studies have shown that HDL and Apo A-I levels are inversely correlated with the risk of developing CAD. Elevated plasma levels of total LDL, as well as lowered levels of HDL, are proven risk factors for atherosclerosis $[9,10]$. Functional distinctions between the plasma lipoproteins are mostly explained by specific combinations of Apo lipoproteins. Therefore, many Apo lipoproteins are crucial in the homeostasis and physiological control of lipid metabolism. Polymorphisms of several of these Apo lipoprotein genes have been studied extensively and shown to be associated with variation in plasma total, LDL and HDL levels. Furthermore, the associations between these gene polymorphisms and the clinical manifestations of atherosclerosis, especially $\mathrm{CAD}$, have been investigated to a considerable extent. However, not much research has been done in SAIs, the group with excess CAD risk. Discovery of novel polymorphisms will help to understand further the causes of excess CAD risk in South Asians so that preventative strategies targeted especially to this high-risk group can be developed.

\section{Acknowledgement}

We would like to thank the participants who contributed their valuable time to further our knowledge in this important study. We are also thankful to the Hindu temples in the relevant regions that supported our study and helped with subject recruitment. We thank the study coordinator Ms. Kuntal Shastri for her help with data collection, as well as the Medical College of Georgia, School of Nursing for their support. This work was funded by the NIH-NHLBI grant (HL091476-0) and start-up funds from the Georgia's Health Sciences University, School of Nursing. 


\section{Financial disclosures}

The authors have nothing to disclose.

\section{References}

[1] K. Jefferys, Annual flow report, DHS office of immigration statistics. 2007. U.S. legal permanent residents, 2006.

[2] P. Joshi, S. Islam, P. Pais, S. Reddy, P. Dorairaj, K. Kazmi, M.R. Pandey, S. Haque, S. Mendis, S. Rangarajan and S. Yusuf, Risk factors for early myocardial infarction in South Asians compared with individuals in other countries, JAMA 297(3) (2007), 286-294.

[3] A. Goyal and S. Yusuf, The burden of cardiovascular disease in the Indian subcontinent, Indian J Med Res 124 (2006), 235-244.

[4] S. Dodani and L. Dong, Impact of acculturation on coronary artery disease in South Asian immigrants, Ethnicity Dis 2011 [In Press].

[5] S.S. Anand, S. Yusuf, V. Vuksan, S. Devanesen, K.K. Teo, P.A. Montague, L. Kelemen, C. Yi, E. Lonn, H. Gerstein and R.A. Hegele, Differences in risk factors, atherosclerosis and cardiovascular disease between ethnic groups in Canada: The Study of Health Assessment and Risk in Ethnic groups (SHARE), Lancet 356 (2000), 279-284.

[6] D. Bhatnagar, I.S. Anand, P.N. Durrington, D.J. Patel, G.S. Wander, M.I. Mackness, F. Creed, B. Tomenson, Y. Chandrashekhar and M. Winterbotham, Coronary risk factors in people from the Indian subcontinent living in West London and their siblings in India, Lancet 345 (1995), 405-409.

[7] S. Petersen, V. Peto and M. Rayner, Coronary heart disease statistics, British Heart Foundation, London: 2004. Available from: http://www.heartstats.org/datapage. asp?id = 1652. [retrieved on December 2010].

[8] U.S. Bedi, S. Singh, A. Syed, H. Aryafar and R. Arora, Coronary artery disease in South Asians: an emerging risk group, Cardiol Rev 14 (2006), 74-80.

[9] T. Tillin, N. Forouhi, D.G. Johnston, P.M. McKeigue, N. Chaturvedi and I.F. Godsland, Metabolic syndrome and coronary heart disease in South Asians, African-Caribbeans and white Europeans: A UK population-based cross-sectional study, Diabetologia 48 (2005), 649-656.

[10] N.G. Forouhi, N. Sattar, T. Tillin, P.M. McKeigue and N. Chaturvedi, Do known risk factors explain the higher coronary heart disease mortality in South Asian compared with European men? Prospective follow-up of the Southall and Brent studies, Diabetologia 49 (2006), 2580-2588.

[11] Y. Liao, D.L. McGee, R.S. Cooper and M.B. Sutkowski, How generalizable are coronary risk prediction models? Comparison of Framingham and two national cohorts, Am Heart $J$ 137(5) (1999), 837-845.

[12] D.J. Gordon, J.L. Probstfield, R.J. Garrison, J.D. Neaton, W.P. Castelli and J.D. Knoke, High-density lipoprotein cholesterol and cardiovascular disease: Four prospective American studies, Circulation 79 (1989), 8-15.

[13] B.J. Ansell, G.C. Fonarow and A.M. Fogelman, High-density lipoprotein: is it always atheroprotective? Curr Atheroscler Rep 8(5) (2006), 405-411.

[14] M. Navab, G.M. Ananthramaiah, S.T. Reddy, B.J. Van Lenten, B.J. Ansell and S. Hama, The double jeopardy of HDL, Ann Med 37(3) (2005), 173-178.
[15] S. Dodani, Coronary artery diseases in Ssouth Asian immigrants: an update on high density lipoprotein role in disease prevention, J Immigrant Health 11(5) (2009), 415-421.

[16] S. Dodani, R. Kaur, S. Reddy, G.L. Reed and N. Mohammad, Can dysfunctional HDL explain high coronary artery disease risk in South Asians? Int J Cardiol 129(1) (2008), 125-132. Epub 2008 Feb 5.

[17] S. Dodani, M. Butler, J. Wick, J. Vacek, K. Gupta, I. Dong and R. Henkhaus, Metabolic syndrome in South Asian Immigrants: More than just low HDL requiring aggressive management, Lipids Health Dis 10 (2011), 45.

[18] P.G. Frank and Y.L. Marcel, Apolipoprotein A-I: structure; -function relationships, J Lipid Res (41) (2000), 853-872.

[19] S. Oikawa, A.J. Mendez, M.C. Cheung, J.F. Oram and E.L. Bierman, Effect on apo AI and apo AI/AII particles on intracellular cholesterol efflux, Circulation 84(suppl II) (1991), II-2711.

[20] P. Puchois, A. Kandoussi, P. Fievet, J.L. Fourrier, M. Bertrand, E. Koren and J.C. Fruchart, Apolipoprotein AI containing lipoproteins in coronary artery disease, Atherosclerosis $\mathbf{6 8}$ (1987), 35-40.

[21] S. Chhabra, R. Narang, R. Lakshmy and N. Das, APOA1-75 $\mathrm{G}$ to A substitution associated with severe forms of CAD, lower levels of HDL and apoA-I among Northern Indians, Dis Markers 21(4) (2005), 169-174.

[22] M. Gonzalez-Ortiz, E. Martinez-Abundis, O. JacquesCamarena, S.O. Hernandez-Gonzalez, I.G. Valera-Gonzalez and M.G. Ramos-Zavala, Prevalence of metabolic syndrome in adults with excess of adiposity: comparison of the Adult Treatment Panel III criteria with the International Diabetes Federation definition, Acta Diabetol 43(3) (2006), 84-86.

[23] D. Lloyd-Jones, R. Adams, M. Carnethon, G. De Simone, T.B. Ferguson, K. Flegal, E. Ford, K. Furie, A. Go, K. Greenlund, N. Haase, S. Hailpern, M. Ho, V. Howard, B. Kissela, S. Kittner, D. Lackland, L. Lisabeth, A. Marelli, M. McDermott, J. Meigs, D. Mozaffarian, G. Nichol, C. O’Donnell, V. Roger, W. Rosamond, R. Sacco, P. Sorlie, R. Stafford, J. Steinberger, T. Thom, S. Wasserthiel-Smoller, N. Wong, J. Wylie-Rosett and Y. Hong, American Heart Association Statistics Committee and Stroke Statistics Subcommittee. Heart disease and stroke statistics - 2009 update: a report from the American heart association statistics committee and stroke statistics subcommittee, Circulation 119(3) (2009), 480-486.

[24] A.I. Del Sol, K.G.M. Moons, M. Hollander, A. Hofman, P.J. Koudstaal, D.E. Grobbee, M.M. Breteler, J.C. Witteman and M.L. Bots, Is carotid intima-media thickness useful in cardiovascular disease risk assessment? The Rotterdam Study Stroke (32) (2001), 1532-1538.

[25] S. Dodani, R. Kaur, G.L. Reed, V. George, G. Sharma and L. Marion, The association of carotid Intima media thickness with dysfunctional HDL in South Asians, Arch Med Science 4(1) (2008), 40-46.

[26] P.J. Touboul, M.G. Hennerici, Meairs, P. Amarenco, N. Bornstein, L. Csiba, M. Desvarieux, S. Ebrahim, M. Fatar, R. Hernandez Hernandez, M. Jaff, S. Kownator, P. Prati, T. Rundek, M. Sitzer, U. Schminke, J.C. Tardif, A. Taylor, E. Vicaut, K.S. Woo, F. Zannad and M. Zureik, Mannheim carotid intima media thickness consensus (2004-2006). An update on behalf of the advisory board of the $3 \mathrm{rd}$ and 4 th watching the risk symposium 13th and 15th European stroke conferences, Mannheim, Germany, 2004, and brussels, belgium, 2006, Cerebrovasc Dis 23 (2007), 75-78.

[27] Expert Panel on Detection, Evaluation, and Treatment of High Blood Cholesterol in Adults, Executive summary of the third 
report of the National Cholesterol Education Program (NCEP) Expert Panel on Detection, Evaluation, and Treatment of High Blood Cholesterol in Adults (Adult Treatment Panel III), JAMA 285 (2001), 2486-2497.

[28] M. Navab, S.Y. Hama, G.P. Hough, G. Subbanagounder, S.T. Reddy and A.M. Fogelman, A cell-free assay for detecting HDL that is dysfunctional in preventing the formation of or inactivating oxidized phospholipids, J Lipid Res 200(42), 13081317.

[29] B.J. Ansell, N. Navab, S. Hama, G. Fonarow, G. Hough, S. Rahmani, R. Mottahedeh, R. Dave, S.T. Reddy and A.M. Fogelman, Inflammatory/anti-inflammatory properties of highdensity lipoprotein distinguish patients from control subjects better than high-density lipoprotein cholesterol levels and are favorably affected by Simvastatin treatment, Circulation (108) (2003), 2751-2756.

[30] S. Dodani, Y.B. Dong and H. Zhu, Can novel Apo A-I polymorphism be responsible for low HDL in South Asian immigrants, Ind J Hum Genet 14(1) (2008), 9-16.

[31] S. Yusuf, S. Hawken, S. Ounpuu, T. Dans, A. Avezum, F. Lanas, M. McQueen, A. Budaj, P. Pais, J. Varigos and L. Lisheng, INTERHEART Study Investigators. Effect of potentially modifiable risk factors associated with myocardial infarction in 52 countries (the interheart study): case-control study, Lancet 364 (2004), 937-952.

[32] S. Kathiresan, O. Melander, D. Anevski, C. Guiducci, N.P Burtt, C. Roos, J.N. Hirschhorn, G. Berglund, B. Hedblad, L. Groop, D.M. Altshuler, C. Newton-Cheh and M. OrhoMelander, Polymorphisms associated with cholesterol and risk of cardiovascular events, N Engl J Med 358 (2008), 1240 124933.

[33] Wellcome Trust Case Control Consortium. Genome-wide association study of 14,000 cases of seven common disease and 3,000 shared controls, Nature 447 (2007), 661-678.

[34] M.J. McQueen, S. Hawken, X. Wang, S. Ounpuu, A. Sniderman, J. Probstfield, K. Steyn, J.E. Sanderson, M. Hasani, E. Volkova, K. Kazmi and S. Yusuf, INTERHEART Study Investigators. Lipids, lipoproteins, and apolipoproteins as risk markers of myocardial infarction in 52 countries (the INTERHEART study): a case-control study, Lancet 372 (2008), 224 233.

[35] A.J. Lusis, A.M. Fogelman and G.C. Fonarow, Genetic basis of atherosclerosis: part II: clinical implications, Circulation 110(14) (2004), 2066-2071.

[36] S.M. Boekholdt, O.W. Souverein, M.W. Tanck, G.K. Hovingh, J.A. Kuivenhoven, R.I. Peters, H. Jansen, P.M. Schiffers, E.E. van der Wall, P.A. Doevendans, P.H. Reitsma, A.H. Zwinderman, J.J. Kastelein and J.W. Jukema, Common variants of multiple genes that control reverse cholesterol transport together explain only a minor part of the variation of HDL cholesterol levels, Clin Genet 69(3) (2006), 263-270.

[37] M. Navab, G.M. Anantharamaiah, S.T. Reddy, B.J. Van Lenten, G. Datta, D. Garber and A.M. Fogelman, Human apolipoprotein A-I and A-I mimetic peptides: potential for atherosclerosis reversal, Curr Opin Lipidol 15(6) (2004 Dec), 645-649.

[38] U.M. Jadhav and N.N. Kadam, Apolipoproteins: Correlation with carotid intima media thickness and coronary artery disease, J Assoc Physicians India 52 (2004), 370-375.

[39] A. Pulkkinen, L. Viitanen, A. Kareinen, S. Lehto and M. Laakso, MspI polymorphism at +83 bp in intron 1 of the human apolipoprotein A1 gene is associated with elevated levels of HDL cholesterol and apolipoprotein A1 in nondiabetic sub- jects but not in type 2 diabetic patients with coronary heart disease, Diabetes Care 23(6) (2000), 791-795.

40] O. Perez-Mendez, E. Bruckert, G. Franceschini, N. Duhal, B. Lacroix, J.P. Bonte, C. Sirtori, J.C. Fruchart, G. Turpin and G. Luc, Metabolism of apolipoproteins AI and AII in subjects carrying similar apoAI mutations, apoAI Milano and apoAI Paris, Atherosclerosis (148) (2000), 317.

[41] G.K. Hovingh, A. Brownlie, R.J. Bisoendial, M.P. Dube, J.H. Levels and W. Petersen, A novel apoA-I mutation (L178P) leads to endothelial dysfunction, increased arterial wall thickness, and premature coronary artery disease, J Am Coll Cardiol 44(7) (2004), 1429-1435.

[42] M.S. Islam, O.T. Raitakari, M. Juonala, M. Kahonen, N. HutriKahonen, A. Collings, K. Aalto-Setälä, K. Kontula, J. Marniemi, J.S. Viikari and T. Lehtimäki, Apolipoprotein A-I/C-III/AIV SstI and apolipoprotein B XbaI polymorphisms and their association with carotid artery intima-media thickness in the Finnish population. The Cardiovascular Risk in Young Finns Study, Atherosclerosis 180(1) (2005), 79-86.

[43] K.Y. Kobayashi, H. Yanagi, H. Fukayama, C. Hirano, Y. Shimakura, N. Yamamoto, T. Arinami, S. Tsuchiya and H. Hamaguchi, Frequent occurrence of hypoalphalipoproteinemia due to mutant apolipoprotein A-I gene in the population: a population-based survey, Human Mol Genet 8(2) (1999), 331-336.

[44] O. Pérez-Méndez, M. Torres-Tamayo, C. Posadas-Romero, V. Vidaure Garcés, E. Carreón-Torres, E. Mendoza-Pérez, A. Medina Urrutia, C. Huesca-Gómez, J. Zamora-González and B. Aguilar-Herrera, Abnormal HDL subclasses distribution in overweight children with insulin resistance or type 2 diabetes mellitus, Clin Chim Acta 376(1-2) (2007), 17-22, Epub 2006 Jul 14.

[45] C.J. Willer, S. Sanna, A.U. Jackson, A. Scuteri, L.L. Bonnycastle, R. Clarke, S.C. Heath, N.J. Timpson, S.S. Najjar, H.M. Stringham, J. Strait, W.L. Duren, A. Maschio, F. Busonero, A. Mulas, G. Albai, A.J. Swift, M.A. Morken, N. Narisu, D. Bennett, S. Parish, H. Shen, P. Galan, P. Meneton, S. Hercberg, D. Zelenika, W.M. Chen, Y. Li, L.J. Scott, P.A. Scheet, J. Sundvall, R.M. Watanabe, R. Nagaraja, S. Ebrahim, D.A. Lawlor, Y. Ben-Shlomo, G. Davey-Smith, A.R. Shuldiner, R. Collins, R.N. Bergman, M. Uda, J. Tuomilehto, A. Cao, F.S. Collins, E. Lakatta, G.M. Lathrop, M. Boehnke, D. Schlessinger, K.L. Mohlke and G.R. Abecasis, Newly identified loci that influence lipid concentrations and risk of coronary artery disease, Nat Genet 40 (2008), 161-169.

[46] S. Kathiresan, O. Melander, D. Anevski, C. Guiducci, N.P. Burtt, C. Roos, J.N. Hirschhorn, G. Berglund, B. Hedblad, L. Groop, D.M. Altshuler, C. Newton-Cheh and M. OrhoMelander, Polymorphisms associated with cholesterol and risk of cardiovascular events, N Engl J Med 358 (2008), 12401249.

[47] R. McPherson, A. Pertsemlidis, N. Kavaslar, A. Stewart, R. Roberts, D.R. Cox, D.A. Hinds, L.A. Pennacchio, A. TybjaergHansen, A.R. Folsom, E. Boerwinkle, H.H. Hobbs and J.C. Cohen, A common allele on chromosome 9 associated with coronary heart disease, Science 316 (2007), 1488-1491.

[48] M. Gomaraschi, D. Baldassarre, M. Amato, S. Eligini, P. Conca, C.R. Sirtori, G. Franceschini and L. Calabresi, Normal vascular function despite low levels of high-density lipoprotein cholesterol in carriers of the apolipoprotein A-I (Milano) mutant, Circulation 116 (2007), 2165-2172.

[49] D. Zabaneh, J.C. Chambers, P. Elliott, J. Scott, D.J. Balding et al., Heritability and genetic correlations of insulin resistance and component phenotypes in Asian Indian families using 
a multivariate analysis, Diabetologia 52(12) (2009), 25822589.

[50] E. Zeggini, L.J. Scott, R. Saxena, B.F. Voight, J.L. Marchini, T. Hu, P.I. de Bakker, G.R. Abecasis, P. Almgren, G. Andersen, K. Ardlie, K.B. Boström, R.N. Bergman, L.L. Bonnycastle, K. Borch-Johnsen, N.P. Burtt, H. Chen, P.S. Chines, M.J. Daly, P. Deodhar, C.J. Ding, A.S. Doney, W.L. Duren, K.S. Elliott, M.R. Erdos, T.M. Frayling, R.M. Freathy, L. Gianniny, H. Grallert, N. Grarup, C.J. Groves, C. Guiducci, T. Hansen, C. Herder, G.A. Hitman, T.E. Hughes, B. Isomaa, A.U. Jackson, T. Jørgensen, A. Kong, K. Kubalanza, F.G. Kuruvilla, J. Kuusisto, C. Langenberg, H. Lango, T. Lauritzen, Y. Li, C.M. Lindgren, V. Lyssenko, A.F. Marvelle, C. Meisinger, K. Midthjell, K.L. Mohlke, M.A. Morken, A.D. Morris, N. Narisu, P. Nilsson, K.R. Owen, C.N. Palmer, F. Payne, J.R. Perry, E. Pettersen, C. Platou, I. Prokopenko, L. Qi, L. Qin, N.W. Rayner, M. Rees, J.J. Roix, A. Sandbaek, B. Shields, M. Sjögren, V. Steinthorsdottir, H.M. Stringham, A.J. Swift, G. Thorleifsson, U. Thorsteinsdottir, N.J. Timpson, T. Tuomi, J. Tuomilehto, M. Walker, R.M. Watanabe, M.N. Weedon and C.J. Willer, Wellcome Trust Case Control Consortium, T. Illig, K. Hveem, F.B. Hu, M. Laakso, K. Stefansson, O. Pedersen, N.J. Wareham, I. Barroso, A.T. Hattersley,
F.S. Collins, L. Groop, M.I. McCarthy, M. Boehnke and D. Altshuler, Meta analysis of genome-wide association data and large-scale replication identifies additional susceptibility loci for type 2 diabetes, Nat Genet 40(5) (2008), 638-645.

[51] Benyamin, T.I.A. Sorensen, K. Schousboe, M. Fenger, P.M. Visscher and K.O. Kyvik, Are there common genetic and environmental factors behind the endo phenotypes associated with the metabolic syndrome? Diabetologia 50(9) (2007), 1880-1888.

[52] D. Zabaneh and D.J. Balding, A genome-wide association study of the metabolic syndrome in Indian Asian men, PLoS One 5(8) (2010), e11961.

[53] M. Deepa, S. Farooq, M. Datta et al., Prevalence of metabolic syndrome using WHO, ATPIII and IDF definitions in Asian Indians: the Chennai Urban Rural Epidemiology Study (CURES-34), Diabetes Metab Res Rev 23(2) (2007), 127-134.

[54] T. Joy, P. Lahiry, R.L. Pollex and R.A. Hegele, Genetics of the metabolic syndrome, Curr Diabetes Rep 8 (2008), 141-148.

[55] T. Nieminen, M. Kähönen and T. Lehtimäki, The effects of apoA-I/C-III/ A-IV, apoE and apoB polymorphisms on carotid artery intima-media thickness, Future Cardiol 2 (2006), 179186. 


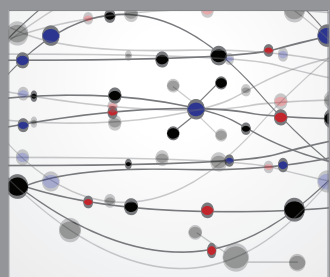

The Scientific World Journal
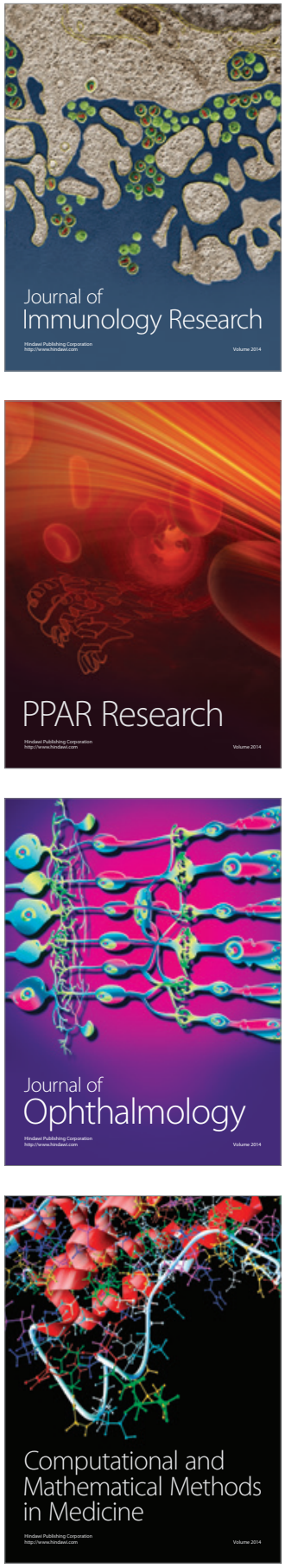

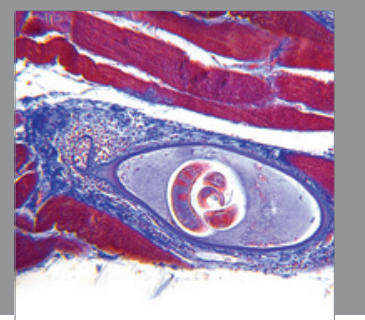

Gastroenterology

Research and Practice
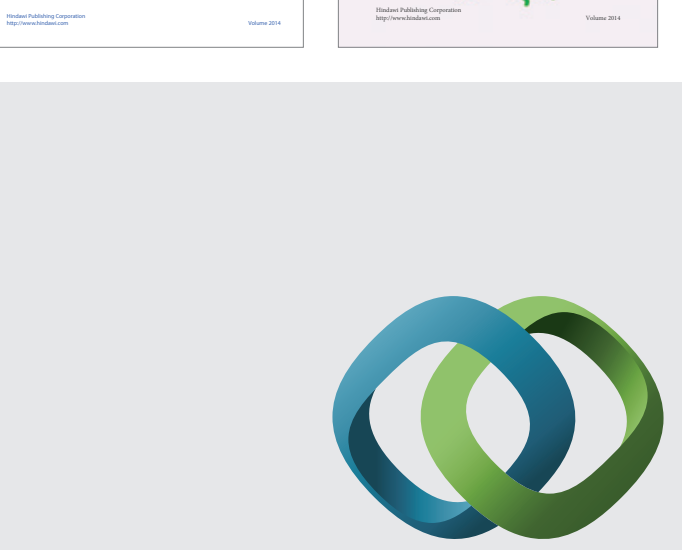

\section{Hindawi}

Submit your manuscripts at

http://www.hindawi.com
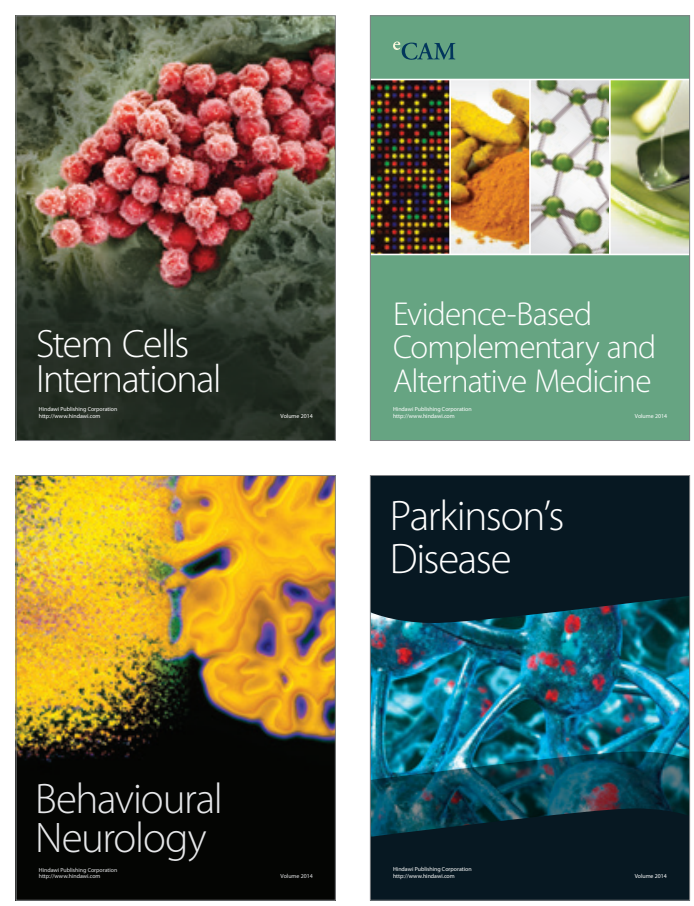

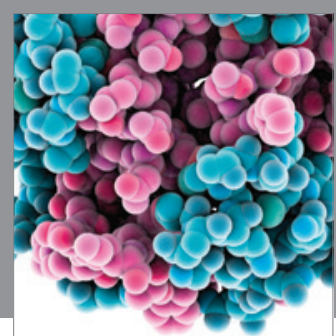

Journal of
Diabetes Research

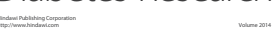

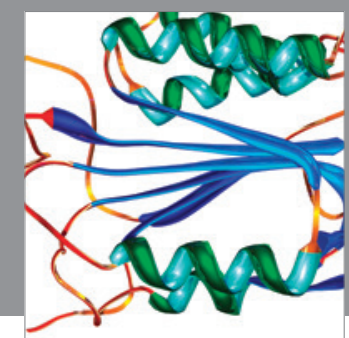

Disease Markers
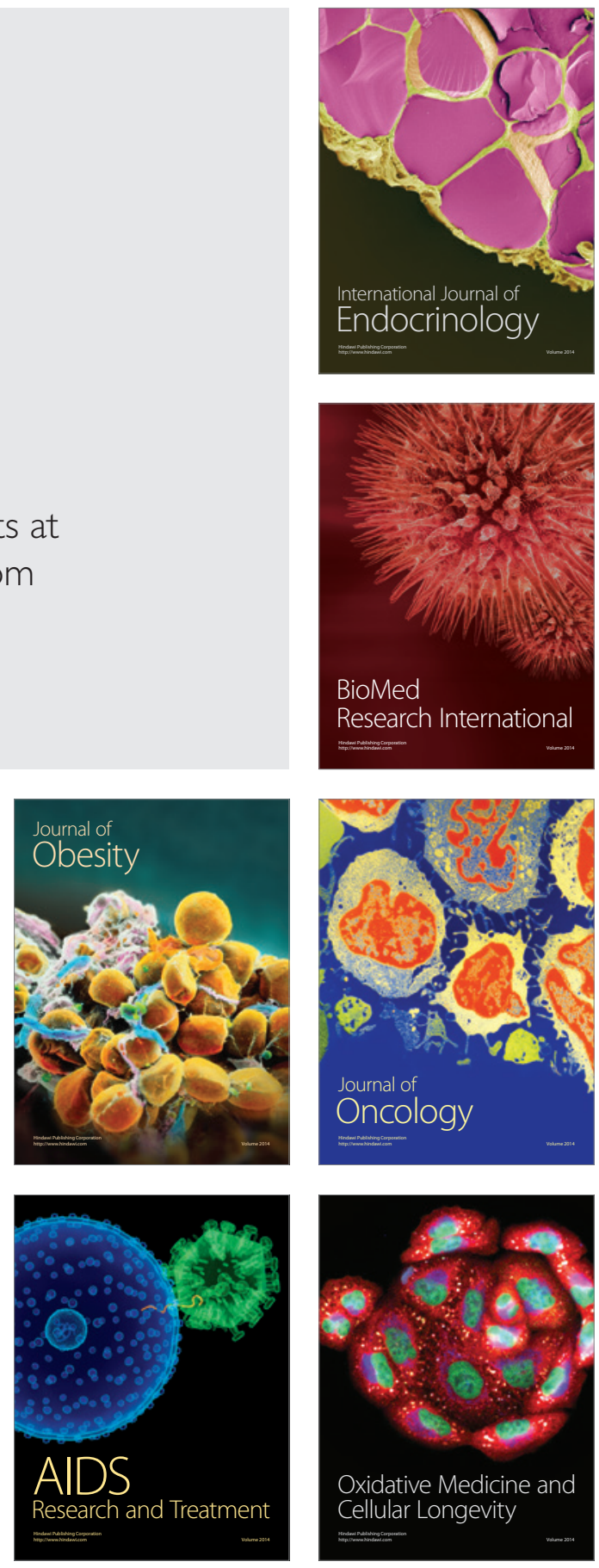